University of Nebraska - Lincoln

DigitalCommons@University of Nebraska - Lincoln

March 1967

\title{
Low Temperature Sample Orienting Device with Two Degrees of Freedom
}

David J. Sellmyer

University of Nebraska-Lincoln, dsellmyer@unl.edu

Follow this and additional works at: https://digitalcommons.unl.edu/physicssellmyer

Part of the Physics Commons

Sellmyer, David J., "Low Temperature Sample Orienting Device with Two Degrees of Freedom" (1967). David Sellmyer Publications. 189.

https://digitalcommons.unl.edu/physicssellmyer/189

This Article is brought to you for free and open access by the Research Papers in Physics and Astronomy at DigitalCommons@University of Nebraska - Lincoln. It has been accepted for inclusion in David Sellmyer Publications by an authorized administrator of DigitalCommons@University of Nebraska - Lincoln. 
To keep the cover, part 2, from falling off when the burner is held upside down, a retainer spring ring, part 7 , is placed between parts 6 and 2. Part 2 is made of aluminum, part 1 is a $3.2 \mathrm{~mm}$ stainless steel tube, part 6 is a Luer mount hypodermic needle No. 27 , and part 3 is a similar hypodermic needle in which the needle was replaced by the part 1 tube.

The burner weighs about $5 \mathrm{~g}$, is about $36 \mathrm{~mm}$ long, and $9 \mathrm{~mm}$ o.d.

Several of the burners described here were successfully used for sealing the capillary tubes mentioned before, for bending and joining small diameter glass tubes and rods, and for soft soldering wires and small brass parts.

Thanks are due to D. Leibovitz and Y. Wolowelsky for helpful suggestions, and to Y. Mokasie for information about fuel gases.

\footnotetext{
${ }^{1}$ Microhematocrit capillaries are $75 \mathrm{~mm}$ long, $1.5 \mathrm{~mm}$ diam, and $1.1 \mathrm{~mm}$ hole diam

${ }^{2}$ Strumia tubes are $30 \mathrm{~mm}$ long, $0.8 \mathrm{~mm}$ diam, and $0.7 \mathrm{~mm}$ hole diam.

${ }^{3}$ D. Danon and X. Marikovsky, J. Lab. Clin. Med. 64, 668 (1964).
}

\section{Low Temperature Sample Orienting Device with Two Degrees of Freedom*}

\section{J. Sellmyer}

Massachusetts Institute of Technology, Cambridge, Massachusetts 02139 (Received 10 October 1966; and in final form, 28 November 1966)

$\mathrm{T}$ HE purpose of this note is to describe a sample orienting device which has been used successfully at liquid helium temperatures to measure the high-field magnetoresistance of several single crystal metallic compounds ${ }^{1}$ in a solenoidal field.

Thorsen and Berlincourt have described an apparatus for measuring de Haas-van Alphen oscillations as a function of crystallographic orientation in a solenoidal field. ${ }^{2}$ Their device permits the field direction to be varied along a single line from, for example, [100] to [001] on the stereogram of Fig. 1. The author has used a sample holder similar to this in measuring the transverse magnetoresistance (current density, $\mathbf{J}$, perpendicular to field, B) of an intermetallic compound in a superconducting solenoid. ${ }^{3}$ If, in a transverse run, $J||[010]$, rotation of the sample means that the field moves along the line through [100] and [001] in Fig. 1.

However, in order to completely investigate the highfield galvanomagnetic properties of a metal and relate them to a given Fermi surface model, one must, subject to symmetry considerations, determine the field dependence of the magnetoresistance for all field directions and several current directions in the crystal. ${ }^{4}$ It is obvious that if only transverse magnetoresistance is measured, a

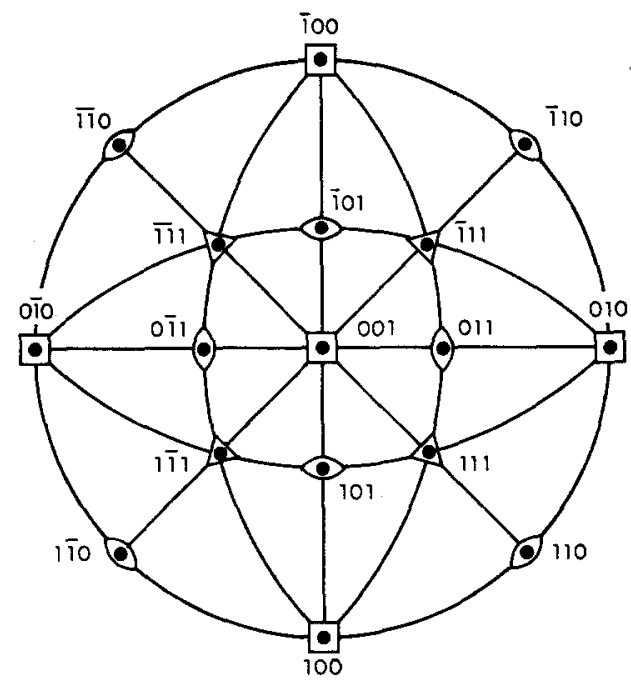

Fig. 1. Stereogram showing field directions for various tip angles as explained in text.

large number of samples having different orientations are required.

The sample holder shown in Fig. 2 permits the field to be pointed in any crystallographic direction for an arbitrary sample axis. This is accomplished with two gears: a worm gear which controls the "tip-angle," $\phi$, and a spiral gear similar to that used by Thorsen and Berlincourt $^{2}$ which controls the angle $\psi$ shown in Fig. 2. If we define the zero of $\psi$ to be the position of the spiral gear as shown in Fig. 2, then it is seen that the tip angle can be changed with drive rod $\mathrm{C}$ only when $\psi=0$. Drive rod $\mathrm{C}$ must be lifted up and locked out of the way while $\psi$ is being changed.

The reason for mounting the sample on a removable insert is to control accurately the crystallographic plane in which the sample is tipped. The cylindrical sample of approximate dimensions $0.15 \times 1 \mathrm{~cm}$ is temporarily fixed to the insert. It is then adjusted by rotating it about its axis, using Laue back-reflection techniques, until a certain axis is parallel to axis $\mathbf{B B}^{\prime}$ in Fig. 2. The sample is then glued to the insert and the insert to the worm gear face with Duco cement. If, for example, a sample with $\mathbf{J} \|$ [010] is mounted so that $[00 \overline{1}] \| \mathrm{BB}^{\prime}$, then [001] is parallel to $\underline{\mathrm{B}}$ at $\psi=90^{\circ}$ for any tip angle. A longitudinalto-transverse run from [010] to [010] can be done when $\phi=90^{\circ}$ and a run passing through $[1 \overline{1} 0],[1 \overline{1} 1]$ and $[001]$ when $\phi=45^{\circ}$.

The diameter of the sample holder is $2.70 \mathrm{~cm}$; it was designed to fit into a double glass liquid helium Dewar which is situated in a $5.08 \mathrm{~cm}$ bore, $150 \mathrm{kG}$ Bitter-type magnet. All the parts of the sample holder are constructed from linen based phenolic. An insulator was used to avoid shielding problems in field modulation experiments and to avoid the shorting problems encountered earlier ${ }^{3}$ with 


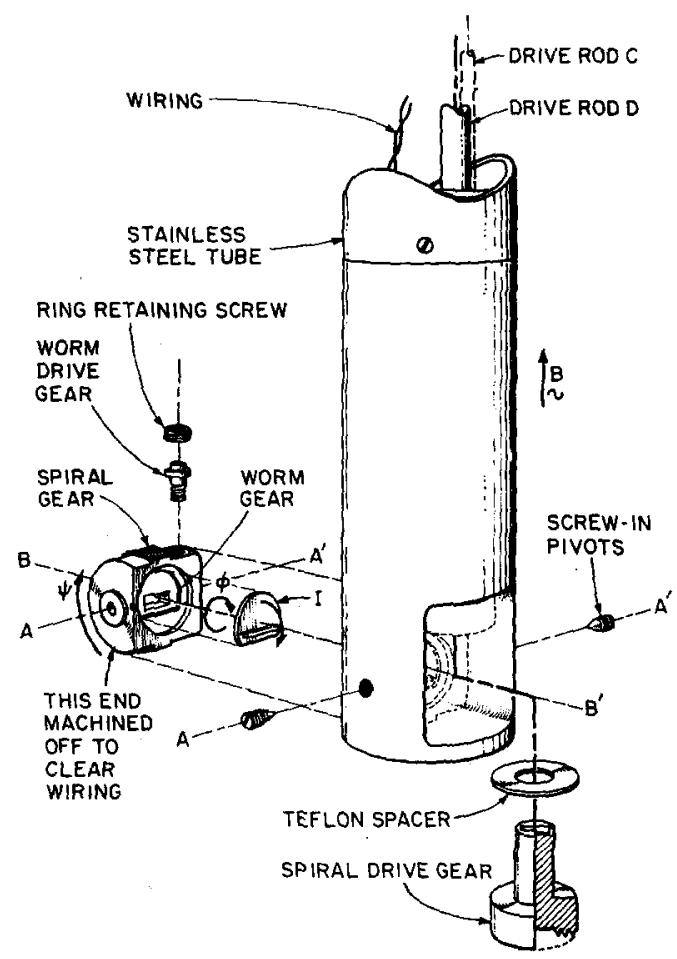

FIg. 2. Exploded view of sample holder. The sample is not shown; it is glued to the "ledge" and face of the insert, I.

the fine current and potential leads. The spiral gear was lubricated with Molykote lubricant $522 \times 302 .{ }^{5}$ It worked quite smoothly at low temperatures unless previously it had been allowed to become damp at room temperatures, causing the phenolic to swell somewhat.

Drive rod $\mathrm{D}$ is connected at the top of the cryostat to a motor whose speed can be varied from about 1 to 3 $\mathrm{rpm}$; a $180^{\circ}$ rotation of the sample can then be made in from 10 to $30 \mathrm{~min}$. Rotation plots were recorded continuously on an $\mathrm{X}-\mathrm{Y}$ recorder with the $\mathrm{X}$ axis signal coming from a linear ten-turn potentiometer coupled to drive rod D. In order to be able to work at temperatures lower than $4.2^{\circ} \mathrm{K}$, it was necessary to bring both of the drive shafts out of the cryostat through vacuum seals. The shafts were brought up through holes in the flange supporting the sample holder. Around the two holes were machined circular grooves which accepted miniature $\mathrm{O}$ rings which fit snugly around the two shafts. The seal was then made against the shafts and flange by tightening a small flange down onto both of the O-rings.

The gears were machined so that one revolution of rods $\mathrm{D}$ and $\mathrm{C}$ corresponds to $\Delta \psi=6.0^{\circ}$ and $\Delta \phi=6.3^{\circ}$, respectively. Including errors in $\mathrm{x}$-raying and spark cutting the samples, it is estimated that the absolute direction of the field relative to the crystalline axes is known to $\pm 2^{\circ}$. However, since in most cases there is sharp structure in the rotation plots as the field is rotated through a high symmetry plane, the position of the sample is usually known to $\pm 0.5^{\circ}$. It is estimated that the spiral gear can be positioned reproducibly to $\pm 0.3^{\circ}$.

I would like to thank P. Kelleher and P. Wilkalis for very skillfully machining this device.

* Supported by the Advanced Research Projects Agency, under contract SD90.

${ }_{1}$ To be published.

${ }^{2}$ A. C. Thorsen and T. G. Berlincourt, Rev. Sci. Instr. 34, 435 (1963).

${ }^{3}$ D. J. Sellmyer and P. A. Schroeder, Phys. Letters 16, 100 (1965).

${ }^{4}$ The use of samples having various current axes is particularly important in compensated metals, i.e., metals whose Fermi surfaces have equal electron and hole volumes.

${ }^{5} \alpha$ Molykote Corporation, Stamford, Connecticut.

\section{Preparation of Thin Film Deuterated Polyethylene Targets*}

\author{
G. E. Tripard $\dagger$ and B. L. White \\ Physics Department, University of British Columbia, \\ Vancouver $8, B$. C.
}

(Received 21 September 1966; and in final form, 24 October 1966)

THIN deuterium targets of about $100 \mu \mathrm{g} / \mathrm{cm}^{2}$ were required for the production of monoenergetic neutron beams using the $\mathrm{D}(\mathrm{d}, \mathrm{n})^{3} \mathrm{He}$ reaction. White ${ }^{1}$ has described the preparation of thin polyethylene films between 900 and $2500 \AA$ thick by vacuum evaporation. The only disadvantage of this technique is that a large fraction of the evaporated polyethylene is lost in the vacuum chamber. Another technique ${ }^{2}$ similar to the one described in this paper was used to prepare targets $1-20 \mathrm{mg} / \mathrm{cm}^{2}$. The main difficulty with the $100 \mu \mathrm{g} / \mathrm{cm}^{2}$ targets is their very poor stability in a charged particle beam due to their very low thermal and electrical conductivity. In the present work, it is shown that the evaporation of a thin film of carbon onto the polyethylene improves the target stability considerably. The targets prepared were capable of withstanding an incident $2 \mathrm{MeV}$ deuteron beam of $200 \mathrm{nA}$ through a $0.318 \mathrm{~cm}$ diam collimator for $1 \mathrm{~h}$ with only a $10 \%$ deterioration of the deuterated polyethylene.

Polyethylene films were prepared by dissolving $0.01 \mathrm{~g}$ of deuterated polyethylene ${ }^{3}\left(\mathrm{C}_{2} \mathrm{D}_{4}\right)_{n}$ in $5 \mathrm{~g}$ of boiling xylene. The solution was kept near the boiling point for 5 min to completely dissolve the polyethylene. While still hot the solution was poured quickly onto process clean micro slides $46 \times 25 \times 1 \mathrm{~mm}$. Five grams of solution were sufficient to cover 6 slides. The slides were set aside in a dust free environment to dry for $24 \mathrm{~h}$.

Using a carbon arc apparatus described by Dearnaley, ${ }^{5}$ a thin carbon film $10 \mu \mathrm{g} / \mathrm{cm}^{2}$ was evaporated onto the polyethylene. The polyethylene film with its thin carbon coating was floated off the glass by lowering the slide slowly into the water at an angle of $30^{\circ}$ to the surface. 